\title{
Educational nutritional intervention program improved the quality of diet of women with breast cancer in adjuvant treatment
}

\section{Programa de intervenção nutricional educativa melhorou a qualidade da dieta de mulheres \\ com câncer de mama em}

\section{tratamento adjuvante}

Sheyla DE LIZ1 ${ }^{1 D}$ 0000-0002-0763-2452

Francilene Gracieli Kunradi VIEIRA ${ }^{1}$ iD) 0000-0003-4211-9133

Ana Paula Gines GERALDO² (ID) 0000-0002-9716-601X

Maria Alice Altenburg de ASSIS ${ }^{1}$ (D) 0000-0002-5383-3714

Patricia Faria DI PIETRO1 (D) 0000-0003-1343-5049

\section{A B S T R A C T}

\section{Objective}

To assess the outcome of an educational nutritional intervention in the quality of diet of women with breast cancer in adjuvant treatment.

\footnotetext{
1 Universidade Federal de Santa Catarina, Departamento de Nutrição, Programa de Pós-Graduação em Nutrição. Campus Universitário, s/n., Trindade, 88040-900, Florianópolis, SC, Brasil. Correspondence to: FGK VIEIRA. E-mail:<francilene.vieira@ufsc.br>.

2 Universidade Federal de Santa Catarina, Centro de Ciências da Saúde, Departamento de Nutrição. Florianópolis, SC, Brasil.

Support: Conselho Nacional de Desenvolvimento Científico e Tecnológico (14/2008); Fundação de Amparo à Pesquisa do Estado de Santa Catarina (15.952/2009); and Coordenação de Aperfeiçoamento de Pessoal de Nível Superior.

Article based on the dissertation of S De LIZ, entitled "Qualidade da dieta de mulheres em tratamento adjuvante para o câncer de mama submetidas a um programa de intervenção nutricional educativa". Universidade Federal de Santa Catarina; 2015.
}

\section{How to cite this article}

De Liz S, Vieira FGK, Geraldo APG, Assis MAA, Di Pietro PF. Educational nutritional intervention program improved the quality of diet of women with breast cancer in adjuvant treatment. Rev Nutr. 2020;33:e190145. https://doi.org/10.1590/1678-9 $865202033 e 190145$ 


\section{Methods}

Women with breast cancer and admitted for surgical treatment were divided in an intervention group ( $\mathrm{n}=18)$ and a comparison group $(n=78)$, and participated in a nonrandomized clinical trial. Participants were assessed before and after the treatment and/or intervention. A food frequency questionnaire was applied and the quality of diet was calculated using the Brazilian Healthy Eating Index Revised. The educational nutritional intervention lasted 12 months and was carried out through phone calls twice a month, personal meetings, and monthly handouts. It oriented an intake of at least $400 \mathrm{~g}$ of vegetables and fruits per day and at most $500 \mathrm{~g}$ of red/ processed meat per week.

\section{Results}

We observed a significant improvement in the diet quality of the intervention group (+5.7). Nutritional education in the intervention group reached its objectives, with a rise in the intake of vegetables and fruits reflecting a significant increase in the score of total fruits (+1.9) and whole fruits (+1.1), and a decrease in the score of meat, eggs, and legumes (-3.3) by means of a reduction in the intake of red/processed meat $(p<0.05)$. Also, a rise in the punctuation of calories from solid fats, alcohol, and added sugar was observed $(+5.0, p<0.05)$ due to lower intake of these components. The comparison group presented no significant differences.

\section{Conclusion}

The nutritional intervention contributed to improving the quality of the diet during breast cancer treatment and possibly altered these women's prognoses.

Keywords: Breast neoplasms. Cancer survivors. Clinical trial. Food consumption. Food habit.

\section{R E S U M O}

\section{Objetivo}

O estudo objetivou analisar o impacto de uma intervenção nutricional educativa na qualidade da dieta de mulheres com câncer de mama em tratamento adjuvante.

\section{Métodos}

Mulheres com câncer de mama admitidas para tratamento cirúrgico, divididas em grupo intervenção (n=18) e grupo comparação (n=78), participaram de um ensaio clínico não randomizado. As participantes foram avaliadas antes e após o tratamento elou intervenção. Um questionário de frequência alimentar foi aplicado, e a qualidade da dieta foi calculada pelo Índice de Qualidade da Dieta Revisado. A intervenção nutricional educativa ocorreu por meio de ligações quinzenais, encontros presenciais e materiais informativos, durante 12 meses, com orientações visando à ingestão de pelo menos 400g/dia de vegetais e frutas, e não mais que 500g/semana de carne vermelha/processada.

\section{Resultados}

O grupo de intervenção melhorou significativamente a qualidade da dieta $(+5,7)$. Além disso, houve aumento da ingestão de frutas e vegetais, representado por elevação significativa na pontuação de frutas totais $(+1,9)$ e frutas integrais $(+1,1)$ e redução considerável na pontuação de carnes, ovos e leguminosas $(-3,3)$, a qual se deu pela diminuição do consumo de alimentos embutidos e carne bovina $(p<0,05)$. Ainda, observou-se aumento na pontuação do componente que avalia as quilocalorias provenientes das gorduras sólidas, bebidas alcoólicas e açúcar de adição $(+5,0, p<0,05)$ devido ao menor consumo desses alimentos. O grupo comparação não apresentou diferenças significativas.

\section{Conclusão}

A intervenção nutricional contribuiu para melhorar a qualidade da dieta durante o tratamento para câncer de mama e, possivelmente, o prognóstico dessas mulheres.

Palavras-chave: Neoplasias da mama. Sobreviventes de câncer. Ensaio clínico. Consumo alimentar. Hábitos alimentares.

\section{NTRODUCTIO N}

Breast cancer is the leading cause of death from cancer in women worldwide [1]. In Brazil, according to the National Cancer Institute, the mortality from breast cancer in 2013 was of 14.35 
deaths per 100,000 women [2]. With the help of early diagnoses associated with more effective forms of treatment, survival rates have increased [1]. The current 5 years survival rate for developed countries is $85 \%$ and in Brazil it has increased to $87 \%$ [3]

Although adjuvant treatment, particularly chemotherapy, is essential to control the growth of tumor cells, it presents a systemic cytotoxic effect that might affect both tumor and healthy cells, which can cause toxicity and adverse effects, such as pain, nausea, and alterations in taste and smell. Those may lead to changes in food intake and patients' nutritional status, possibly worsening prognoses and increasing the risk of disease recurrence $[4,5]$.

During adjuvant treatment, different eating behaviors were verified, such as the increased intake of energy-dense and nutrient-poor foods and decrease in the intake of fiber-rich and antioxidant foods like fruits, vegetables, and whole grains $[6,7]$. The current evidence suggests that a higher intake of red meat, fat, and alcohol can indicate risk factors, while a higher intake of fruits and vegetables can help lower the risk of cancer recurrence, due to antioxidant nutrients $[6,8,9]$.

Considering nutritional changes during adjuvant treatment, nutritional education is important to improve diet quality and decrease the risk of breast cancer recurrence $[8,10-12]$. Since nutritional interventions in women with breast cancer focus on various diet components [10-12], their effectiveness may be measured by instruments of global diet assessment, such as dietary indexes, making it possible to vastly evaluate food intake $[13,14]$. In this context, dietary indexes have been used to assess associations between diet quality and breast cancer [15-18]. Few studies, however, use dietary indexes to assess the quality of diets after an educational nutritional program $[19,20]$, especially for breast cancer [15], even though such indexes have been proven effective for this type of evaluation. Thus, this article assesses the outcome of an educational nutritional intervention program in the quality of diet of women with breast cancer in adjuvant treatment.

\section{METHO D S}

A nonrandomized clinical trial was performed with women with breast cancer admitted for surgical treatment in the Carmela Dutra Hospital, Florianópolis - Brazil, between 2006 and 2011. Written consent was provided in all the phases of the study and it was approved both by the Ethics Committee of the Federal University of Santa Catarina (099/2008; 492/2009) and the Ethics Committee of the Carmela Dutra Hospital (0012.0.233.242-10).

Two groups were evaluated in the study: the Intervention Group (IG) is composed of women with breast cancer who underwent educational nutritional intervention for twelve months and who were evaluated right before breast cancer surgery (TO) and after nutritional intervention and adjuvant treatment (T1) [10]; the Comparison Group (CG) is composed of women with breast cancer evaluated right before breast cancer surgery (T0) and after (T1) adjuvant treatment $[21,22]$ (from nine to fourteen months, according to the duration of the treatment) (Figure 1). More details about the recruitment and selection of the participants can be obtained in a previous study [10].

The nutritional intervention was described in a previous study [10]. In brief, the intervention lasted 12 months and it provided dietary recommendations in an educational way, based on the guidelines of the World Cancer Research Fund (WCRF) and the American Institute for Cancer Research (AICR) [8]. The intervention was based specifically on two WCRF/AICR guidelines to facilitate understanding and adherence by the participants: daily intake of at least $400 \mathrm{~g}$ of a variety of fruits and vegetables (excluding fruit juices and starchy vegetables) and the weekly intake of no more than $500 \mathrm{~g}$ of red or processed meat [10]. It is important to highlight that "red meat" refers to beef, 


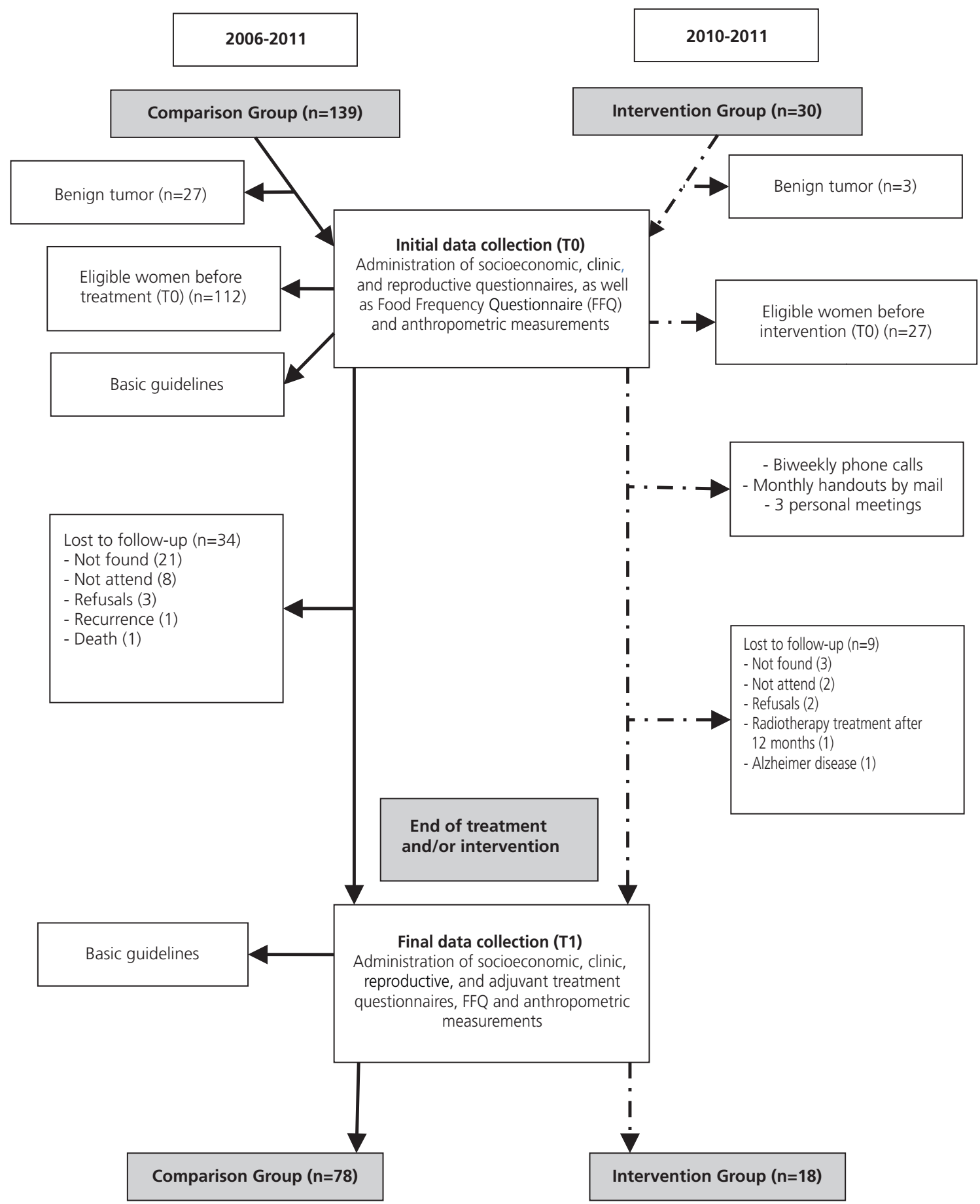

Figure 1. Study design. Florianópolis (SC), Brazil, 2015. 
pork, lamb, and goat meat, whereas "processed meat" includes meat preserved by smoking, curing, salting, or the addition of chemical preservatives $[8,10]$.

To facilitate the participants' understanding, the recommendations were provided in appropriate language, using common domestic forms of food measurement. To reach the recommendations for fruits and vegetables, participants were encouraged to consume at least two servings of fresh fruits (2 units), a small plate of raw vegetables, and two servings (2 spoonful) of cooked vegetables daily [10]. They were also recommended to limit the intake of red and processed meat to twice a week (1 medium size steak each time) in order to reach the recommendations for red or processed meat [10].

In the first personal interview (TO), domestic models of food measurement of different sizes and commonly employed and a photo album [23] were used to facilitate future approaches by phone (detailed below) [10]. Each woman received a 12-month calendar so they were able to daily write down how often they consumed fruits, vegetables, and red/processed meat, as a form of selfcontrolling their eating habits, as well as to improve their participation in research [10].

After the first contact, biweekly phone calls were made for each woman, following a standard protocol [10]. To begin with, the researcher asked if they were able to eat normally and how they were feeling in relation to treatment. After that, the objectives of the intervention were reviewed. At the end of the phone call, the researcher recommended an increase in the amount of fruits/ vegetables and a reduction in the intake of red or processed meats, if necessary [10]. Furthermore, every three months, two 24-hours dietary recalls were applied by phone - one in a weekday and the other at the weekend, to qualitatively assess their dietary intake and to provide personalized recommendations for women, according to the intervention goals [10].

The IG received monthly handouts by mail, which were prepared in easy language and contained scientific evidence concerning several topics. These materials included tips on food preparation and healthy recipes, as a way of encouraging a healthier diet that matched the intervention's goals. Also, information on the role of food in the prevention of breast cancer recurrence and reduction of the side effects of the treatment was provided [10].

Three personal meetings occurred over the 12 months. In these meetings, lectures were performed, and educational materials and extra healthy recipes were distributed; healthy snacks were offered as to encourage a healthier lifestyle. Women who did not participate in the meetings had access to all printed materials by mail [10]. For the CG, handouts in understandable language containing general guidelines about healthy eating for breast cancer prevention [10] were provided before the two interviews (T0 and T1). Questionnaires developed in previous studies [21,22] to collect clinical and therapeutic data were identically applied to both groups in T0 and T1 by trained interviewers. Weight and height measurements were performed according to standard procedures [24]. Body Mass Index (BMI) was used to evaluate the weight status according to the World Health Organization [25].

Data concerning food intake was obtained from a Food Frequency Questionnaire (FFQ) validated and adapted for Brazilian adults [26], which evaluates consumption in the previous year. This evaluation refers to 12 months before (TO) and after (T1) surgery for breast cancer in the IG and CG. Food items from FFQ were converted into daily intake frequency (in grams or milliliters) [10]. The daily intake of seasonal foods, as vegetables and fruits, were calculated proportionally to the crop period [10], according to the following formula: $\{[$ (daily consumption frequency * $\mathrm{n}$ days harvest period $)$ * $(n$ days harvest period/365)] * (grams or milliliters of food)\}.

The FFQ was administered by trained interviewers using a photo album [23] and models of domestic food measurement in order to facilitate the identification of food serving sizes [10]. The 
Brazilian Table of Food Composition [27] and the Table of the US Department of Agriculture [28] were used to calculate the nutritional composition of the consumed foods.

Since the applied FFQ does not present a topic related to added salt, and the nutrient database more commonly used [27] does not consider the added salt in food preparation, sodium intake was adjusted for salt used in cooking, as performed in a previous study [29]. These amounts were adjusted in the food items from the FFQ, whenever necessary, according to what is reported on the literature for added salt in food preparation [30].

The assessment of the diets' quality was performed using the Brazilian Healthy Eating Index Revised (BHEI-R) [31], which was proven to be a reliable and valid instrument to assess and follow diet quality in Brazil [32]. Briefly, the BHEI-R consists of 12 components. The following nine food groups are included in the Brazilian Dietary Guidelines [33]: (1) total fruits (includes fruit and fruit juice); (2) whole fruits (except fruit juice); (3) total vegetables (includes legumes only after the standard for the meat, eggs, and legumes component is met); (4) dark green and orange vegetables, and legumes (includes legumes only after the standard for the meat, eggs, and legumes component is met); (5) total grains; (6) whole grains; (7) milk and dairy products (includes all milk products and soy-based beverages); (8) oils (includes non-hydrogenated vegetable oils, as well as fish, nuts, and seeds oils); and (9) meat, eggs, and legumes. The maximum score for is five points each for the first six components and ten points each for the last three components. The higher the intake, the higher the score. The two remaining components are based exclusively on nutrients: (10) sodium and (11) saturated fat, with a maximum score of ten points. The last component represents (12) the total dietary energy derived from Solid Fats, Alcohol, and Added Sugar (SoFAAS) with a maximum score of twenty points. These three components indicate an unhealthy diet and thus, a lower intake receives higher scores. For all components, intermediate scores were calculated proportionately to the quantity consumed. Finally, scores of each component are summed to determine the total score, which varies between zero and 100 points. Higher scores represent better diet qualities [31].

All food items from the FFQ were grouped according to the BHEI-R components. Food items from the FFQ compound of one or more food and/or form of preparation had their ingredients separated according to three tested recipes [34]. After that, the average amount in grams or milliliters of each ingredient was classified according to the corresponding component of BHEI-R [31].

The scores of each BHEI-R component were calculated based on energy density per 1,000kcal, considering the energy value of a serving size according to the recommendation of the Brazilian Dietary Guidelines [33], except for three components: saturated fat and SoFAAS (calculated as a percentage contribution of Total Energy Value), and sodium (calculated in milligrams per 1,000kcal). Total score was obtained by adding the score of the BHEI-R components [31].

The score of the meat, eggs, and legumes component used to calculate the total BHEI-R score encompasses all meat items from the FFQ (red meat, processed meat, chicken, fish, seafood, and eggs). However, to assess the effectiveness of the nutritional intervention, the score of each type of meat was analyzed to observe which contributed the most to the meat, eggs, and legumes component score. Thus, the food items from the FFQ were subdivided according to type of food in: red and processed meat (beef or pork with or without fat, hamburger/ground beef, sausage, ham, mortadella, and offal - liver, stomach, heart, and viscera); and other meats (fried or boiled eggs; chicken, with or without fat; fish, with or without fat; and seafood - shrimp, oysters, sardines, tuna, cockle, and mussel).

Absolute and relative frequency was used for the expressed categorical variables, whereas median and Interquartile Range (IR) or means and Standard Deviation (SD) were applied for continuous variables, according to the normality of data (Kolmogorov-Smirnov Test). Inter-group baseline analyses 
(T0) were compared by the $t$ test, Fisher's EXACT test, or chi-square test. The Mann-Whitney test was applied for comparisons by median change. Wilcoxon test or paired $t$ test were used for intra-group comparisons ( $\mathrm{T} 0$ and $\mathrm{T} 1$ ). The statistically significant $p$ value was $<0.05$ and the statistical tests were performed in Stata ${ }^{\circledR} 11.0$ Software (StataCorp, College Station, TX, 2009).

\section{R E S U L T S}

The IG was composed of 18 participants (mean $=49.6$ years, SD=10.9 years) and the CG was composed of 78 women (mean $=51.9, \mathrm{SD}=11.4$ years). Non-significant differences between groups were identified at baseline (Table 1).

The Table 2 shows the comparison between the groups and the change in the BHEI-R total score and components. In regard to the quality of diets, we observed that the women in the IG

Table 1. Baseline clinical, anthropometric, and therapeutic characteristics of women participants ( $n=96)$. Florianópolis (SC), Brazil, 2015.

\begin{tabular}{|c|c|c|c|c|c|}
\hline \multirow{2}{*}{ Characteristics } & \multicolumn{2}{|c|}{ IG $(n=18)$} & \multicolumn{2}{|c|}{ CG $(n=78)$} & \multirow{2}{*}{$p$} \\
\hline & Mean & $\pm S D$ & Mean & $\pm S D$ & \\
\hline Age (years) & 49.6 & \pm 10.9 & 51.9 & \pm 11.4 & $0.446^{\ddagger}$ \\
\hline Weight (Kg) & 72.0 & \pm 14.7 & 69.3 & \pm 12.7 & $0.431^{\neq}$ \\
\hline \multirow[t]{2}{*}{$\mathrm{BMI}\left(\mathrm{Kg} / \mathrm{m}^{2}\right)$} & 28.9 & \pm 4.6 & 27.7 & \pm 4.8 & $0.356^{\ddagger}$ \\
\hline & $\mathrm{n}$ & $\%$ & $\mathrm{n}$ & $\%$ & \\
\hline Tumor classification & & & & & $0.641^{*}$ \\
\hline Invasive carcinoma & 16 & 88.9 & 72 & 92.3 & \\
\hline Carcinoma in situ & 2 & 11.1 & 6 & 7.7 & \\
\hline Tumor stage & & & & & $0.918^{\dagger}$ \\
\hline 0 & 1 & 5.6 & 2 & 2.6 & \\
\hline I & 6 & 33.3 & 27 & 34.6 & \\
\hline$\|$ & 7 & 38.9 & 29 & 37.2 & \\
\hline III & 4 & 22.2 & 20 & 25.6 & \\
\hline Axillary lymph node involvement & & & & & $0.345^{\dagger}$ \\
\hline Positive & 5 & 27.8 & 31 & 39.7 & \\
\hline Negative & 13 & 72.2 & 47 & 60.3 & \\
\hline Surgical procedure & & & & & $0.562^{\dagger}$ \\
\hline Radical mastectomy ${ }^{1}$ & 6 & 42.9 & 40 & 51.3 & \\
\hline Partial mastectomy or axillary lymphadenectomy ${ }^{2}$ & 8 & 57.1 & 38 & 48.7 & \\
\hline Radiotherapy and/or chemotherapy & & & & & $0.362^{\dagger}$ \\
\hline \multicolumn{6}{|l|}{ Yes } \\
\hline Radiotherapy & 3 & 16.7 & 18 & 23.1 & \\
\hline Chemotherapy & 2 & 11.1 & 21 & 26.9 & \\
\hline Radiotherapy in association with chemotherapy & 11 & 61.1 & 34 & 43.6 & \\
\hline No & 2 & 11.1 & 5 & 6.4 & \\
\hline Hormone therapy ${ }^{3}$ & & & & & $0.820^{\dagger}$ \\
\hline \multicolumn{6}{|l|}{ Yes } \\
\hline Tamoxifen & 12 & 70.6 & 50 & 64.1 & \\
\hline Aromatase inhibitor & 1 & 5.9 & 8 & 10.3 & \\
\hline No & 4 & 23.5 & 20 & 25.6 & \\
\hline
\end{tabular}

Note: ${ }^{*}$ Fisher's exact test; ${ }^{\ddagger} t$ test; ${ }^{\dagger}$ Chi-square test; ${ }^{1}$ Complete removal of breast and axillary lymph nodes; ${ }^{2}$ Quadrantectomy or sector resection with Sentinel Lymph node Biopsy (SLB) and/or complete removal of axillary lymph nodes; ${ }^{3} \mathrm{IG}: \mathrm{n}=17$.

BMI: Body Mass Index; CG: Comparison Group; IG: Intervention Group; SD: Standard Deviation. 
Table 2. Comparison of changes in the scores (total and by components) for Brazilian Healthy Eating Index Revised. Florianópolis (SC), Brazil, 2015.

\begin{tabular}{|c|c|c|c|c|c|c|c|c|}
\hline \multirow{2}{*}{ BHEI-R and components } & \multicolumn{2}{|c|}{ TO } & \multicolumn{2}{|c|}{ T1 } & \multirow{2}{*}{$p^{\dagger}$} & \multicolumn{2}{|c|}{ Change } & \multirow{2}{*}{$p^{\#}$} \\
\hline & $\mathrm{M}$ & $\pm \mathrm{SD}$ & $\mathrm{M}$ & $\pm S D$ & & Median & $\mathrm{IR}$ & \\
\hline \multicolumn{9}{|l|}{ BHEI-R total score } \\
\hline IG & 72.0 & \pm 8.7 & 77.7 & \pm 6.9 & $0.021^{\mathrm{s}}$ & 6.2 & $1.6 ; 10.0$ & 0.007 \\
\hline CG & 75.7 & \pm 8.7 & 75.2 & \pm 8.9 & $0.645^{\$}$ & 0.4 & $-4.9 ; 5.0$ & \\
\hline
\end{tabular}

BHEI-R components scores

Whole fruits

IG

CG

Total fruits
IG
CG

Total vegetables

IG

CG

Dark green and orange vegetables and legumes

IG

CG

Total grains

IG

CG

Whole grains

IG

CG

Milk and Dairy products

IG

CG

Oils

IG

CG

Sodium

IG

CG

Saturated fat

IG

CG

SOFAAS

IG

CG

Meat, eggs and legumes$$
\text { IG }
$$

$3.6 \pm 1.4$

$4.6 \pm 0.9$
$4.7 \quad \pm 1.0$

$\pm 1.0$

$4.5 \pm$
$0.002^{5}$

$0.173^{5}$
0.9

$0.0 ; 1.9<0.001$

$0.0 \quad 0.0 ; 0.0$

\begin{tabular}{llllll}
\hline Median & $\mathbb{R}$ & Median & $\mathbb{R}$ & Median & $\mathbb{R}$ \\
\hline
\end{tabular}

\section{3.}

4.8

$5.0 \quad 2.5 ; 5.0$

$5.0 \quad 2.9 ; 5.0$

$\begin{array}{ll}5.0 & 4.6 ; 5.0 \\ 5.0 & 4.5 ; 5.0\end{array}$

5.0

5.0

$4.4 ; 5.0$

0.700

0.0

0.0

$-1.0 ; 0.0$

$5.0 \quad 5.0 ; 5.0$

5.0

$5.0 ; 5.0$

0.181

0.0

$0.0 ; 0.0$

$5.0 \quad 5.0 ; 5.0$

5.0

$5.0 ; 5.0$

0.603

0.0

$0.0 ; 0.0$

$0.0 \quad 0.0 ; 0.2$

$\begin{array}{lll}0.1 & 0.0 ; 0.8 & 0.303\end{array}$

0.0

$0.0 ; 0.0$

$0.0 \quad 0.0 ; 0.5$

0.0

$0.0 ; 0.5$

0.842

0.0

$0.0 ; 0.0$

$4.4 \quad 3.0-6.0$

\section{$4.7 \quad 2.8-7.3$}

$3.6 \quad 2.3-4.6$

0.249

$-0.7$

$-2.7 ; 1.1$

$-0.3$

$-2.3 ; 0.5$

10.0

$10.0 ; 10.0$

10.0

$10.0 ; 10.0$

0.317

0.0

$0.0: 0.0$

0.0

$0.0 ; 0.0$

\section{$8.5 \quad 7.4 ; 8.9$}

$8.7 \quad 7.1 ; 9.5$

9.7

7.4; 10.0

0.191

$9.8 \quad 8.6 ; 10.0<0.001$

0.9

$-0.4 \cdot 1.5$

0.511

$6.6 \quad 4.5 ; 8.8$

$6.9 \quad 4.3 ; 9.1$

$9.1 \quad 7.0 ; 10.0 \quad 0.001$

$8.6 \quad 7.0 ; 10.0<0.001$

1.5

0.7

$0.5 ; 4.2$

0.091

$14.2 \quad 10.6 ; 17.7$

$19.2 \quad 16.4-20.0 \quad 0.033$

2.5

0.0

$0.0 ; 6.7$

0.030

$17.4 \quad 13.5 ; 20.0$

17.8

$13.9-20.0$

0.843

$6.7 \quad 5.9 ; 9.8<0.001$

$-1.8$

$-3.6 ; 0.0$

0.251

$7.0 \quad 4.8 ; 9.6 \quad<0.001$

$-1.1 \quad-2.3 ; 0.0$

Note: ${ }^{\top}$ Wilcoxon test. ${ }^{\$}$ Paired $t$ test. ${ }^{\#}$ Mann-Whitney test. T0: Before nutritional intervention and/or adjuvant treatment; T1: After nutritional intervention and/or adjuvant treatment.

BHEI-R: Brazilian Healthy Eating Index Revised; CG: Comparison Group; IG: Intervention Group; IR: Interquartile Range; M: Mean; SD: Standard Deviation; SoFAAS: total dietary energy derived from solid fats, alcohol, and added sugar. 
increased significantly their BHEI-R total mean score ( +5.7 points, $p=0.021)$, thus improving the quality of their diets. On the other hand, no changes were observed in the CG after treatment (T1). In addition, the change in inter-groups BHEI-R total median score was significant $(p=0.007)$, with the IG presenting a higher increase $(6.2[I R: 1.6 ; 10.0])$ in relation to the CG $(0.4[I R:-4.9 ; 5.0])$.

After nutritional intervention, the IG improved its diet quality by a significant increase in the scores of the following components in relation the baseline: whole fruits $(+1.1)$, total fruits $(+1.9)$, saturated fat $(+2.5)$, and SoFAAS (+5.0). The last two components represent unhealthy diets, thus higher scores represent a lower intake. Moreover, the IG presented significant decreases in the meat, eggs, and legumes component (-3.3).

Concerning intra-group changes ( $\mathrm{T} 0$ and $\mathrm{T} 1$ ), the $\mathrm{CG}$ presented a significant increase in the score of sodium $(+1.1)$ and saturated fat $(+1.7)$ in relation to the baseline. This means a decrease in the intake of such ingredients; in other words, an improvement in the quality related to these components. However, the CG presented a significant decrease in the score of total vegetables (-1.7), as well as in the consumption of milk and dairy products (-1.2), thus leading to a reduction in the quality of their diets. When it comes to the CG, one could still observe a significant decrease in the score of the meat, eggs, and legumes (-1.8) component during treatment. Significant differences between groups were identified concerning the median scores of the components whole fruits, total fruits, and SoFAAS. For these components, the IG presented more significant changes when compared to the CG.

As previously mentioned, we could observe a significant median decrease in the score of the meat, eggs, and legumes component for both groups. This is due to a decrease in the median intake of red and processed meats confirmed by a significant decrease in the score of this subgroup in relation to meat, eggs, and legumes (Table 3). The decrease in the median intake of red and processed meats has collaborated to a substantial rise in the saturated fat component score for both groups (IG: +2.5 vs. CG: +1.7 ), and in the SoFAAS component score specifically for the IG group (+5.0) (Table 2). Significant changes were not observed in the IG in terms of weight $(\mathrm{kg})$ and $\mathrm{BMI}$, whereas the CG presented significant increases in these parameters. No inter-groups significant differences were presented (data not shown).

Table 3. Comparison of changes in the score for food subgroups meat, eggs, and legumes* component of Brazilian Healthy Eating Index Revised. Florianópolis (SC), Brazil, 2015.

\begin{tabular}{|c|c|c|c|c|c|c|c|c|}
\hline \multirow{2}{*}{ Food subgroups } & \multicolumn{2}{|c|}{ TO } & \multicolumn{2}{|c|}{$\mathrm{T} 1$} & \multirow{2}{*}{$p^{\dagger}$} & \multicolumn{2}{|c|}{ Change } & \multirow{2}{*}{$p^{\#}$} \\
\hline & Median & IR & Median & IR & & Median & IR & \\
\hline \multicolumn{9}{|c|}{ Red and processed meat ${ }^{1}$} \\
\hline IG & 4.0 & $3.6 ; 5.5$ & 2.1 & $1.4 ; 3.0$ & 0.001 & -1.7 & $-3.6 ;-1.0$ & 0.146 \\
\hline CG & 3.7 & $1.9 ; 5.4$ & 2.1 & $1.2 ; 4.2$ & 0.003 & -1.0 & $-2.9 ; 0.8$ & \\
\hline \multicolumn{9}{|l|}{ Other meats ${ }^{2}$} \\
\hline IG & 4.0 & $3.3 ; 5.6$ & 3.8 & $3.3 ; 5.3$ & 0.711 & -0.3 & $-1.6 ; 0.4$ & 0.822 \\
\hline CG & 3.2 & $2.2 ; 4.6$ & 3.2 & $2.4 ; 4.9$ & 0.475 & -0.3 & $-1.4 ; 1.3$ & \\
\hline
\end{tabular}

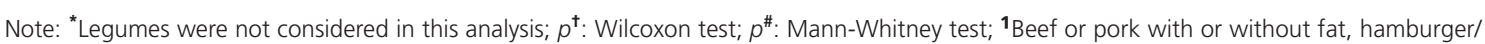
ground beef, sausage, ham, mortadella, and offal (liver, stomach, heart, and viscera); ${ }^{2}$ Fried or boiled eggs; chicken (with or without fat), fish (with or without fat); and seafood (shrimp, oysters, sardines, tuna, cockle, and mussel); T0: Before nutritional intervention and/or adjuvant treatment; T1: After nutritional intervention and/or adjuvant treatment.

CG: Comparison Group; IG: Intervention Group; IR: Interquartile Range. 


\section{DISCUSSION}

The educational nutritional intervention was effective to augment the consumption of fruits and reduce the consumption of red and processed meat of women facing breast cancer adjuvant treatment. These were confirmed by the significant modifications in the punctuation of BHEI-R components that reflected the main goals of the intervention. However, the intervention goal of increasing the vegetable intake was not achieved. Both groups showed a decrease in the total vegetables score, although it was only significant in the CG. Chemotherapy has variable influence on appetite and both taste sensitivity and perceived intensity of the taste qualities $[4,5,35,36]$, which may have influenced the vegetables intake. Nevertheless, the nutritional intervention may have contributed to the maintenance of total vegetables score in the IG during treatment.

During breast cancer adjuvant treatment, particularly chemotherapy - the most frequent form of therapy used by the women participating in this research (IG: $72.2 \%$; CG: 70.5\%)-, changes in patients' food intake $[6,7,22]$ incur in modifications in the quality of their diets. In this study, the IG demonstrated a significant rise in the mean total count of the BHEI-R, whereas no differences were observed for the CG. Significant differences in the total score median between groups were also observed. These findings suggest that the nutritional intervention had the effect of improving the diet quality of women in the IG. Such results were also found in the study conducted by Snyder et al. [15] in the United States, which assessed the effectiveness of a nutritional intervention for a 12 -month follow-up, aiming to ameliorate the global diet quality between older cancer survivors ( $\geq 65$ years, breast or prostate cancer), as measured by the Diet Quality Index-Revised (DQI-R). In that study, the intervention group $(n=89)$ received nutritional guidelines via workbooks and phone calls, based on the DQI-R components. The authors pointed out that the DQI-R was helpful in guiding dietary counseling and observed significant differences in the overall diet quality after intervention, an increase in the intervention group (67.6 $\pm 12.2 \mathrm{vs}$. $69.8 \pm 13.9$ points; $p=0.003)$, and a decrease in the control group (67.5 \pm 2.5 vs. $64.6 \pm 4.7$ points; $p=0.003)$ [15].

There is a shortage of nutritional intervention studies conducted right after diagnosis [10], as was done in the present study. Moreover, we found one single clinical study of nutritional interventions using a dietary index to assess the quality of diets amongst breast cancer survivors [15]. However, such study was conducted with individuals within 18 months of their diagnoses, not necessarily right after the diagnosis. The lack of similar studies makes it difficult to perform a comparison of results. That, on the other hand, reflects the originality of this research. As mentioned earlier, antineoplastic treatment may cause changes in patients' food intake. Thus, the nutritional intervention provided immediately after diagnosis might be an important contribution to the improvement of prognoses.

The present study highlights a significant improvement in the diet quality of the IG after intervention when compared to the CG, due to a rise in the punctuation of total fruits, whole fruits, and SoFAAS. Even though both groups presented a significant increase in the saturated fat and a decrease in the meat, eggs, and legumes scores - confirmed by a significant cut in the median intake of red and processed meats -, the IG presented the most significant changes when compared to the $C G$. These findings suggest that the nutritional intervention contributed to improve the diet quality of such women, since the changes in the BHEI-R components correspond to the recommendations provided throughout the intervention period.

These outcomes corroborate the ones from the randomized clinical trial conducted by Mohammadshahi et al. [37], which investigated the effects of a 3-month nutritional intervention 
on the diet quality of Iranian obese women $(n=60)$, measured by the Healthy Eating Index 2005 (HEI-2005), and also on inflammation biomarkers. In this study, the group that received the intervention ( $n=30)$ gained a booklet and attended weekly nutrition education classes (1 hour/week). The program was based on recommendations for a healthier diet according to the dietary guidelines for Iranian people. The authors observed that the group that received the recommendations improved its diet quality, with significant rises in all HEl-2005 components, except total grains, which did not increase significantly. Also, total score and total vegetables, dark green and orange vegetables and legumes, total fruits, milk, whole grain, meat and beans, saturated fat, sodium, and SoFAAS components presented higher and significant scores in relation to the control group [37].

Some studies performed in people with chronic diseases - not including breast cancer -, use dietary indexes to evaluate the effect of nutritional interventions, obtaining effective results [19,20], as in this study. The study of Mecca et al. [19] investigated the effectiveness of a lifestyle intervention focusing on physical activity and high fiber intake to reduce indicators of metabolic syndrome in overweight/obese individuals in the city of Botucatu (São Paulo, Brazil). The Healthy Eating Index modified for the Brazilian population was utilized to measure the quality of the sample's diets. This study demonstrated that the intervention group presented a higher improvement in the total score ( $77 \pm 16$ vs. $97 \pm 11$ points; $p<0.05)$ and in the component fruits and vegetables $(231(0 ; 937)$ vs. 539 $(127 ; 909) \mathrm{g} / \mathrm{d} ; \mathrm{p}<0.05)$ in relation to the baseline. Other study [20] evaluated the effect of a 3-month lifestyle intervention in hypercholesterolaemic adults from Athens (Greece), on physical activity levels and diet quality, the latter assessed using the HEI-2005. The findings of that study showed that the intervention group significantly improved their total score and the milk component score in comparison to the control group. Also, the intervention group improved the whole grain $(1.3 \pm 1.9$ vs. $1.9 \pm 2.0$ points) and SoFAAS (13.9 \pm 7.4 vs. $16.6 \pm 5.6$ points) components in relation to the baseline [20].

The BHEI-R is considered reliable and structurally valid to evaluate and monitor Brazilian people's diet quality [32]. However, according to the population and intervention in question, some attention is needed while consulting such index. In this context, the meat, eggs, and legumes component includes foods which have intake restriction for people with cancer, such as red and processed meat. In the present study, when it comes to the meat, eggs, and legumes component, the interpretation of the score is accomplished inversely in relation to the original BHEI-R; that is, lower scores reflect better quality of the diet, since a decrease in the score of the meat, eggs, and legumes component is inversely proportional to a decrease in the median intake of red and processed meat. Thus, it is suggested that nutritional interventions applied to cancer patients can also be assessed by food and subgroups of food that contribute to a change in the scores of the components. Dietary factors are one of the modifiable factors that affect a breast cancer prognosis. The current cancer prevention recommendations suggest a predominantly plant-based diet, rich in whole grains and fibers; a diet limited in fat and energy-dense foods; limited intake of red and processed meat, and alcoholic drinks $[8,9,38]$. With these guidelines in mind, health promotion-focused nutritional interventions during treatment may be important to improve prognoses and, perhaps, to decrease the risk of recurrence [39].

The positive changes in the diet quality of women who underwent the educational nutritional intervention program observed in the current study may have collaborated to the maintenance of body weight and BMI in the IG, while significant increases in such parameters were observed in the CG. According to the guidelines, keeping the body weight and BMI is important to improve the prognosis and prevent disease recurrence risk $[8,9]$. A meta-analysis [40] investigated the association 
of diet quality indexes and the risk of cancer mortality. Their findings showed highest scores of adherence to the Healthy Eating Index (HEI-2005, 2010), and the Alternative Healthy Eating Index (AHEI) was significantly associated with a reduction in the risk of cancer mortality (HEI $=$ RR: $0.80,95 \%$ $\mathrm{Cl}: 0.76-0.83 ; \mathrm{AHEI}=\mathrm{RR}: 0.85,95 \% \mathrm{Cl}: 0.83-0.88$ ). From the results of that meta-analysis and of the present study, educational nutritional intervention during breast cancer treatment seems essential to improve diet quality, perhaps improving prognoses and cutting cancer survivors' risk of death.

Preparing meals at home using in natura and minimally processed ingredients has been linked to a rise in the intake of vegetables and whole grains, thus leading to a healthier lifestyle [41-43]. Thus, nutritional intervention protocols based on culinary have been used to improve the general population's diet quality $[44,45]$ and, therefore, were taken into account in the construction of the monthly handouts sent to the participants of this study.

The approaches used in these materials, such as the addition of recipes that stimulated the use of fruits, vegetables, chicken, and fish, using appropriate cooking techniques for the preservation of nutrients, may have been substantial for the results achieved by the intervention proposed in this study. This cannot be related to personal meetings, as the adherence to these meetings was low ( 3 women attended the first and second meetings; 4 women attended the third meeting). The low adherence was attributed to the lack of physical motivation during adjuvant treatment, as reported by the women. Although general and punctual, the handouts given to the CG may have contributed to the improvements in this group, related to the decrease of red and processed meat and saturated fat intake.

A limitation of this study was the small sample size. Furthermore, the study was not randomized, since data were collected at different times for both groups. Nevertheless, it is important to note that the data collection was carried out by trained researchers using the same questionnaires and in the same place. Despite the advantages presented by the instrument, the FFQ method cannot precisely determine the absolute food intake. It also has other intrinsic limitations that may bias the estimative of food intake and interfere with diet quality (it depends on memory, does not take intrapersonal variation of daily food intake into account, it is not precise in estimating portion sizes, and calculation relies on the content of the applied food table). In this study, methodological procedures were carefully performed to ensure greater reliability and accuracy of data. Another point is that, on average, the population evaluated had high scores for the sodium component. Considering dietary habits, this is not in agreement with what is observed in the Brazilian population, which suggests that the method used to assess salt intake in this research may have led to an underestimation of such intake by participants. However, adjustments were made to estimate the salt added to the preparations, as recommended in the literature.

\section{CONCLUSION}

Findings this study showed an improvement in the overall diet quality. Also, the nutritional intervention was effective to achieve the main goals of this research and it contributed to the maintenance of anthropometric parameters in women during adjuvant treatment for breast cancer. The improvement in the BHEI-R components for the IG may be a direct result of the approaches used during the intervention period, mainly the twice-a-month phone calls and monthly booklets. These noninvasive methodologies might help reduce the risk of breast cancer recurrence and improve the prognostic of such women. 


\section{ACKNOWLEDGMENT}

We would like to thank the Mastology Staff of the Carmela Dutra Hospital for their support and we immensely thank the women with breast cancer who agreed to participate in this study for their dedication and collaboration.

\section{CONTRIBUTORS}

S DE LIZ and FGK VIEIRA were responsible for the conception and design of the study and writing the manuscript. All authors contributed to the analysis and interpretation of the data, critical revision of the manuscript, and approved the final version submitted for publication.

\section{R E FER E N CES}

1. Bray F, Ferlay J, Soerjomataram I, Siegel RL, Torre LA, Jemal A. Global Cancer Statistics 2018: GLOBOCAN estimates of incidence and mortality worldwide for 36 cancers in 185 countries. CA Cancer J Clin. 2018;68(6):394-424. http://doi.org/10.3322/caac.21492

2. Instituto Nacional de Câncer José Alencar Gomes da Silva. Monitoramento das ações de controle do câncer de mama. Linha de Cuidado e Rede de Atenção ao Câncer de Mama: boletim 6. 2015 [citado 2016 nov 10];(3). Disponível em: https://www.inca.gov.br/sites/ufu.sti.inca.local/files//media/document//informativodeteccao-precoce-3-2015.pdf

3. Instituto Nacional de Câncer José Alencar Gomes da Silva. Estimativa 2016: Incidência de Câncer no Brasil. Rio de Janeiro; 2015 [citado 2016 nov 10]. Disponível em: https://www.inca.gov.br/bvscontrolecancer/ publicacoes/edicao/Estimativa_2016

4. Boltong A, Aranda S, Keast R, Wynne R, Francis PA, Chirgwin J, et al. A prospective cohort study of the effects of adjuvant breast cancer chemotherapy on taste function, food liking, appetite and associated nutritional outcomes. Plos One. 2014;9(7):e103512. http://doi.org/10.1371/journal.pone.0103512

5. Drareni K, Dougkas A, Giboreau A, Laville M, Souquet PJ, Bensafi M. Relationship between food behavior and taste and smell alterations in cancer patients undergoing chemotherapy: a structured review. Semin Oncol. 2019;46(2):160-72. http://doi.org/10.1053/j.seminoncol.2019.05.002

6. Cicco P, Catani MV, Gasperi V, Sibilano M, Quaglietta M, Savini I. Nutrition and breast cancer: a literature review on prevention, treatment and recurrence. Nutrients. 2019;11(7):e1514. http://doi.org/10.3390/ nu11071514

7. Vance V, Campbell S, McCargar L, Mourtzakis M, Hanning R. Dietary changes and food intake in the first year after breast cancer treatment. Appl Physiol Nutr Metab. 2014;39:707-14. http://doi.org/10.1139/apnm2013-0400

8. World Cancer Research Fund International. Food, nutrition, and the prevention of cancer: a global perspective. Washington: WCRF; 2007 [cited 2016 Nov 10]. Available from: https://www.wcrf.org/dietandcancer/about

9. World Cancer Research Fund/American Institute for Cancer Research. Continuous update project expert report 2018. Diet, nutrition, physical activity and breast cancer survivors. Washington: WCRF; 2014 [cited 2019 Nov 5]. Available from: https://www.wcrf.org/sites/default/files/Breast-cancer-survivors-report.pdf

10. Schiavon CC, Vieira FGK, Ceccatto V, Liz S, Cardoso AL, Sabel C, et al. Nutrition education intervention for women with breast cancer: effect on nutritional factors and oxidative stress. J Nutr Educ Behav. 2015;47(1):2-9. http://doi.org/10.1016/ j.jneb.2014.09.005

11. Hwang ES, Nho JH. Lifestyle intervention for breast cancer women. J Lifestyle Med. 2019;9(1):12-4. http:// doi.org/10.15280/jlm.2019.9.1.12

12. Limon-Miro AT, Lopez-Teros V, Astiazaran-Garcia H. Dietary guidelines for breast cancer patients: a critical review. Adv Nutr. 2017;8(4):613-23. http://doi.org/10.3945/an.116.014423

13. Gil A, Martinez de Victoria E, Olza J. Indicators for the evaluation of diet quality. Nutr Hosp. 2015;31(3):128-44. http://doi.org/10.3305/nh.2015.31.sup3.8761 
14. Ocke MC. Evaluation of methodologies for assessing the overall diet: dietary quality scores and dietary pattern analysis. Proc Nutr Soc. 2013;72(2):191-9. http://doi.org/10.1017/S0029665113000013

15. Snyder DC, Sloane R, Haines PS, Miller P, Clipp EC, Morey MC, et al. The diet quality index-revised: a tool to promote and evaluate dietary change among older cancer survivors enrolled in a home-based intervention trial. J Am Diet Assoc. 2007;107:1519-29. http://doi.org/10.1016/j.jada.2007.06.014

16. George SM, Irwin ML, Smith AW, Neuhouser ML, Reedy J, McTiernan A, et al. Postdiagnosis diet quality, the combination of diet quality and recreational physical activity, and prognosis after early-stage breast cancer. Cancer Causes Control. 2011;22(4):589-98. http://doi.org/10.1007/s10552-011-9732-9

17. Kim EH, Willett WC, Fung T, Rosner B, Holmes MD. Diet quality indices and postmenopausal breast cancer survival. Nutr Cancer. 2011;63:381-88. http://doi.org/10.1080/01635581.2011.535963

18. Shahril MR, Sulaimana S, Shaharudina SH, Akmal SN. Healthy eating index and breast cancer risk among Malaysian women. Eur J Cancer Prev. 2013;22:342-47. http://doi.org/10.1097/CEJ.0b013e32835b37f9

19. Mecca MS, Moreto F, Burini FHP, Dalanesi RC, McLellan KCP, Burini RC. Ten-week lifestyle changing program reduces several indicators for metabolic syndrome in overweight adults. Diabetol Metab Syndr. 2012;4(1):1-7. http://doi.org/10.1186/1758-5996-4-1

20. Petrogianni M, Kanellakis S, Kallianioti K, Argyropoulou D, Pitsavos C, Manios Y. A multicomponent lifestyle intervention produces favourable changes in diet quality and cardiometabolic risk indices in hypercholesterolaemic adults. J Hum Nutr Diet. 2013;26:596-605. http://doi.org/10.1111/jhn.12041

21. Vieira FGK, Di Pietro PF, Boaventura BCB, Ambrosi C, Rockenbach G, Fausto MA, et al. Factors associated with oxidative stress in women with breast cancer. Nutr Hosp. 2011;26(3):528-36. http://doi.org/10.1590/ S0212-16112011000300015

22. Rockenbach G, Di Pietro PF, Ambrosi C, Boaventura BC, Vieira FG, Crippa CG, et al. Dietary intake and oxidative stress in breast cancer: before and after treatments. Nutr Hosp. 2011;26(4):737-44. http://doi. org/10.1590/S0212-16112011000400011

23. Zabotto CB, Viana RPT, Gil MF. Registro fotográfico para inquéritos dietéticos: utensílios e porções. Campinas: Unicamp; 1996.

24. World Health Organization. Physical status: the use and interpretation of anthropometry. Geneva: Organization; 1995.

25. World Health Organization. Obesity: preventing and managing the global epidemic: report of a WHO Consultation on obesity. Geneva: Organization; 2000.

26. Sichieri R, Everhart JE. Validity of a Brazilian food frequency questionnaire against dietary recalls and estimated energy intake. Nutr Res. 1998;18(10): 1649-59. http://doi.org/10.1016/S0271-5317(98)00151-1

27. Núcleo de Estudos e Pesquisas em Alimentação. Tabela brasileira de composição de alimentos. 4 ed. Campinas: Unicamp; 2011 [citado 2016 nov 18]. Disponível em: http://www.nepa.unicamp.br/taco/tabela. php?ativo=tabela

28. Department of Agriculture, Agricultural Research Service. National Nutrient Database for Standard Reference, release 18. Beltsville: Nutrient Data Laboratory; 2005 [cited 2016 Nov 20]. Available from: http://www.ars. usda.gov/ba/bhnrc/ndl

29. Guenther PM, Kirkpatrick SI, Reedy J, Krebs-Smith SM, Buckman DW, Dodd KW, et al. The healthy eating index-2010 is a valid and reliable measure of diet quality according to the 2010 dietary guidelines for Americans. J Nutr. 2014;144:399-407. http://doi.org/10.3945/jn.113.183079

30. Domene SMA. Técnica dietética: teoria e aplicações. Rio de Janeiro: Guanabara Koogan; 2011.

31. Previdelli AN, Andrade SC, Pires MM, Ferreira SRG, Fisberg RM, Marchioni DM. A revised version of the healthy eating index for the Brazilian population. Rev Saude Publ. 2011;45(4):794-98. http://doi.org/10.1590/ S0034-89102011005000035

32. Andrade SC, Previdelli AN, Marchioni DM, Fisberg RM. Evaluation of the reliability and validity of the Brazilian healthy eating index revised. Rev Saúde Pública. 2013,47:675683. http://doi.org/10.1590/\$0034-8 910.2013047004267

33. Ministério da Saúde. Secretaria de Atenção à Saúde ((Brasil). Guia alimentar para a população brasileira: promovendo a alimentação saudável. Brasília; 2008 [citado 2016 nov 05]. Disponível em: http://bvsms. saude.gov.br/bvs/publicacoes/guia_alimentar_populacao_brasileira_2008.pdf 
34. Fisberg RM, Slater B. Manual de receitas e medidas caseiras para cálculo de inquéritos alimentares: manual elaborado para auxiliar o processamento de dados de inquéritos alimentares. São Paulo: Signus; 2002.

35. Boltong A, Keast R. The influence of chemotherapy on taste perception and food hedonics: a systematic review. Cancer Treat Rev. 2012;38(2):152-63. http://doi.org/10.1016/j.ctrv.2011.04.008

36. Vries YC, Van Den Berg MMGA, Vries JHM, Boesveldt S, Kruif JTCM, Buist N, et al. Differences in dietary intake during chemotherapy in breast cancer patients compared to women without cancer. Sup Care Cancer. 2017;25(8):2581-91. http://doi.org/10.1007/s00520-017-3668-x

37. Mohammadshahi M, Haidari F, Karandish M., Ebrahimi S, Haghighizadeh MH. A randomized clinical trial of nutrition education for improvement of diet quality and inflammation in Iranian obese women. J Nutr Metab. 2014;605782:1-10. http://doi.org/10.1155/2014/605782

38. Limon-Miro AT, Lopez-Teros V, Astiazaran-Garcia H. Dietary Guidelines for breast cancer patients: a critical review. Adv Nutr. 2017;8(4):613-23. http://doi.org/10.3945/an.116.014423

39. Xu L, Peterson LL. The Impact of diet on breast cancer outcomes. Curr Nutr Rep. 2019;8(3):212-21. http:// doi.org/10.1007/s13668-019-00278-0

40. Onvani S, Haghighatdoost F, Surkan PJ, Larijani B, Azadbakht L. Adherence to the Healthy Eating Index and Alternative Healthy Eating Index dietary patterns and mortality from all causes, cardiovascular disease and cancer: a meta-analysis of observational studies. J Hum Nutr Diet. 2017;30:216-26. http://doi.org/10.1111/ jhn.12415

41. Mills S, Brown $\mathrm{H}$, Wrieden W, White M, Adams J. Frequency of eating home cooked meals and potential benefits for diet and health: cross-sectional analysis of a population-based cohort study. Int I Behav Nutr Phys Act. 2017;14(1):109. http://doi.org/10.1186/s12966-017-0567-y

42. Alencar B, Toral N, Recine E, Rizzolo A. Factors related to food involvement in the adult population. Rev Nutr. 2016;29(3):337-45. http://doi.org/10.1590/1678-98652016000300004

43. Raber M, Chandra J, Upadhyaya M, Schick V, Strong LL, Durand C, et al. An evidence-based conceptual framework of healthy cooking. Prev Med Rep. 2016;4:23-8. http://doi.org/10.1016/j.pmedr.2016.05.004

44. Reicks M, Trofholz AC, Stang JS, Laska MN. Impact of cooking and home food preparation interventions among adults: outcomes and implications for future programs. J Nutr Educ Behav. 2014;46(4):259-76. http://doi.org/10.1016/j.jneb.2014.02.001

45. Surgenor D, Hollywood L, Furey S, Lavelle F, McGowan L, Spence M, et al. The impact of video technology on learning: a cooking skills experiment. Appetite. 2017;114:306-12. http://doi.org/10.1016/j.appet.2017. 03.037 